University of Nebraska - Lincoln

DigitalCommons@University of Nebraska - Lincoln

Publications from USDA-ARS / UNL Faculty

U.S. Department of Agriculture: Agricultural

Research Service, Lincoln, Nebraska

2012

\title{
Alkaline extraction of phenolic compounds from intact sorghum kernels
}

Deidre L. Blackwell

Agricultural Research Service, deidre.blackwell@ars.usda.gov

Thomas Herald

USDA-Grain Marketing and Production Research Center, tom.herald@ars.usda.gov

Scott R. Bean

Agricultural Research Service, scott.bean@ars.usda.gov

Prini Gadgil

Agricultural Research Service, prini.gadgil@ars.usda.gov

Follow this and additional works at: https://digitalcommons.unl.edu/usdaarsfacpub

Blackwell, Deidre L.; Herald, Thomas; Bean, Scott R.; and Gadgil, Prini, "Alkaline extraction of phenolic compounds from intact sorghum kernels" (2012). Publications from USDA-ARS / UNL Faculty. 1094. https://digitalcommons.unl.edu/usdaarsfacpub/1094

This Article is brought to you for free and open access by the U.S. Department of Agriculture: Agricultural Research Service, Lincoln, Nebraska at DigitalCommons@University of Nebraska - Lincoln. It has been accepted for inclusion in Publications from USDA-ARS / UNL Faculty by an authorized administrator of DigitalCommons@University of Nebraska - Lincoln. 


\title{
Alkaline extraction of phenolic compounds from intact sorghum kernels
}

\author{
Deidre L. Blackwell, Thomas J. Herald,* Scott R. Bean \& Prini Gadgil \\ Center for Grain and Animal Health Research (CGAHR), Agricultural Research Service (ARS), United States Department of Agriculture \\ (USDA), 1515 College Avenue, Manhattan, KS, 66502, USA
}

(Received 6 January 2012; Accepted in revised form 2 June 2012)

Keywords Antioxidant activity, cereal grains, polyphenols, sorghum.

\section{Introduction}

Sorghum (Sorghum bicolor L. Moench) is a major drought-resistant food crop in Africa and Asia. In Western countries, sorghum is utilised as animal feed but is a viable ingredient alternative in gluten-free foods and biofuels (O'Kennedy et al., 2006). The high level of phytochemicals in sorghum kernels is found in the bran and germ (Dykes \& Rooney, 2006). A range of phenolic compounds in sorghum offering antioxidant capacity (AOC) includes phenolic acids, flavonoids, anthocyanins and tannins (Awika \& Rooney, 2004). Phenolic compounds have been extracted from cereal grains using various techniques such as aqueous alcohol (Medina, 2011; Cuevas Montilla et al., 2011) and enzymes (Cuevas Montilla et al., 2011). However, these methods require grain kernels to be processed into meal or flour prior to analysis. Decortication, a mechanical method, is often cited as a means to isolate the phytochemicalrich bran from the grain (Awika et al., 2005). Yet, decortication is an abrasive method of bran removal and may be less efficient for grains with a softer pericarp (Mwansaru et al., 1988). Researchers have reported success in using alkali solutions to remove bran and improve milling yields in corn (Blessin et al., 1970; Mistry \& Eckhoff, 1992), but in the literature, there are no available data concerning the evaluation of the waste streams obtained by a chemical debranning process for phenolic compounds. The

\footnotetext{
*Correspondent: Fax: + 1 (785) 537-5534;

e-mail: tom.herald@ars.usda.gov

Names are necessary to report factually on available data; however, the U.S. Department of Agriculture neither guarantees nor warrants the standard of the product, and use of the name by the U.S. Department of Agriculture implies no approval of the product to the exclusion of others that may also be suitable.
}

objective of this study is to explore the application of $\mathrm{NaOH}$ extraction for sorghum bran removal and phenolic compounds recovered from the waste stream.

\section{Materials and methods}

\section{Chemicals and materials}

Sodium hydroxide $(\mathrm{NaOH})$, acetone, sodium phosphate dibasic and sodium phosphate monobasic were obtained from Fisher Scientific (Fair Lawn, NJ, USA). Glacial acetic acid, hydrochloric acid $(\mathrm{HCl})$, Trolox ${ }^{\circledR}$ (6-hydroxy-2,5,7,8-tetramethylchromane-2-carboxylic acid), fluorescein disodium, 2,2'-azobis(2-amidinopropane) dihydrochloride (AAPH), and black opaque and clear 96-well plates were purchased from SigmaAldrich (St. Louis, MO, USA).

Four sorghum (three non-tannin and one tannin) samples were chosen based on their colours (white, red, brown and black) and known range of phenolic compound content (low to high). Before treatment, grain hardness for each sorghum sample (fifty kernels) was determined using a single-kernel characterisation system (SKCS 4100) from Perten Instruments, Springfield, IL, USA (Pedersen et al., 1996; Bean et al., 2006). For comparison, other cereal grains (black rice, indigo maize and hard red winter wheat) were included in the analysis to show that AOC could be determined. All the grain samples were supplied by USDA-ARSCenter for Grain \& Animal Health Research, Manhattan, KS, USA.

\section{Sodium hydroxide extraction}

Phenolic compounds were extracted using a modified method by Lazaro \& Favier (2000). Approximately 
$5 \mathrm{~g}$ of grain was steeped in $20 \mathrm{~mL}$ of $10 \% \mathrm{NaOH}$ while being shaken and incubated (Labnet International Vortemp 1550, Edison, NJ, USA) at $60{ }^{\circ} \mathrm{C}$ for $10 \mathrm{~min}$. The $\mathrm{NaOH}$ extract (supernatant) was reserved for further analysis, and the grains were washed with hot tap water. Alkaline-treated grains were neutralised by vortexing for $5 \mathrm{~min}$ in $10 \mathrm{~mL}$ glacial acetic acid. The hot water wash was repeated and the grains left to air dry at ambient conditions. $\mathrm{NaOH}$ extracts were either neutralised using $6 \mathrm{M} \mathrm{HCl}$ to approximately $70 \%$ of the original concentration or untreated and diluted to $70 \%$ with deionised (DI) water. An aliquot of the neutralised and untreated samples was freeze dried. Prior to analysis, the freeze-dried extracts were rehydrated back to the initial volume with DI water. Liquid samples were analysed for AOC at days 0,4 , 16 and 32. The freeze-dried treatments were analysed 32 days after extraction. Analysis of the freeze-dried samples was delayed to simulate a reasonable storage scenario. Indigo maize, Karl red wheat and black rice were used as a point of initial reference to compare the sorghum treatments. The sodium hydroxide extraction for the other cereal grains was performed using the same procedure as the sorghum; however, the samples were only analysed on day 0 without carrying out the neutralisation or drying steps.

\section{Sorghum flour extraction}

Sorghum flour samples were prepared by grinding the grain using a UDY cyclone mill 181 (UDY Corporation, Fort Collins, CO, USA) with a $0.5-\mathrm{mm}$ screen. The whole-grain flour $(0.3 \mathrm{~g})$ was suspended in $10 \mathrm{~mL}$ of $75 \%$ acetone, shaken for $2 \mathrm{~h}$ using a MaxQ 2500 shaker (Thermo Fisher Scientific, Waltham, MA, USA) and stored at $-20{ }^{\circ} \mathrm{C}$ overnight. Extracts were centrifuged at $2900 \mathrm{~g}$ for $10 \mathrm{~min}$. The supernatant was saved and the extraction process was repeated the next day on the residues to improve recovery. In the second extraction, $10 \mathrm{~mL}$ of $75 \%$ acetone and the residues were shaken for $10 \mathrm{~min}$. Both supernatants were pooled for a total volume of $20 \mathrm{~mL}$.

\section{Oxygen radical absorbance capacity}

The Oxygen radical absorbance capacity (ORAC) assay was similar to the procedure described by Huang et al. (2002). A solution of $153 \mathrm{~mm}$ AAPH in $75 \mathrm{~mm}$ sodium phosphate buffer $(\mathrm{pH}$ 7.4) was prepared fresh daily. A $4 \times 10^{3} \mathrm{~mm}$ fluorescein stock solution in $75 \mathrm{~mm}$ sodium phosphate buffer ( $\mathrm{pH}$ 7.4) was wrapped in foil and stored at $5{ }^{\circ} \mathrm{C}$. A working solution of diluted fluorescein $(1: 1000)$ in $75 \mathrm{~mm}$ sodium phosphate buffer $(\mathrm{pH}$ 7.4) was prepared daily. Exterior wells of the 96-well plate were filled with $300 \mu \mathrm{L}$ of DI water. Fluorescein solution $(150 \mu \mathrm{L})$ was added to all samples, blanks and standard wells. Solutions $(25 \mu \mathrm{L})$ of diluted extract, phosphate buffer and diluted Trol$\mathrm{ox}^{\circledR}$ were added to samples, blanks and standard wells, respectively, for a total volume of $175 \mu \mathrm{L}$. Equilibration of the plate was performed by incubating at $37{ }^{\circ} \mathrm{C}$ for $30 \mathrm{~min}$ using a Synergy 2 microplate reader (Biotek Instruments Inc., Winooski, VT, USA). All experimental wells were injected with $35 \mu \mathrm{L}$ of AAPH solution using the plate reader injector and shaken for $10 \mathrm{~s}$ at maximum intensity. Fluorescence was monitored at $485 \mathrm{~nm}$ (excitation) and $528 \mathrm{~nm}$ (emission) with measurements taken from the top every $60 \mathrm{~s}$ for $1 \mathrm{~h}$. ORAC values were calculated as described by Cao \& Prior (1999) using the plate reader Gen5 Data Reduction Software (BioTek Instruments) with a standard curve $(0-100 \mu \mathrm{M})$ of Trolox ${ }^{\circledR}$. ORAC values were expressed in $\mu \mathrm{mol}$ TE per $\mathrm{g}$ of grain or flour.

\section{Statistical analysis}

All data were plotted and statistical analysis was conducted using Microsoft Excel 2007 (Microsoft Corporation, Redmond, WA, USA) and OriginPro 8 (OriginLab Corporation, Northampton, MA, USA). Two replications with two subsamples of each treatment were analysed.

\section{Results and discussion}

\section{Extraction method}

The purpose of this method was to determine the efficacy of an alkaline steeping process for the direct extraction of phenolic compounds from intact wholegrain sorghum. Thus, the benefit of the method is the ability to remove the bran and associated phenolic compounds without a physical debranning process. After the alkaline extraction, no visual colour change was exhibited by the white sorghum, whereas the grain of the red sorghum, Sumac (containing tannin), and black sorghum lost virtually all their colour.

\section{Grain mass}

The kernel mass was monitored for 8 days after extraction to assure dryness (data not shown). There was a clear difference in $\Delta$ mass between the lighter- and darker-coloured sorghums (Table 1). The white and red sorghum hybrids had little mass loss, whereas the Sumac and black sorghum had a larger mass loss that stayed relatively constant over the week. Differences in $\Delta$ mass may be due to variations in pericarp thickness and/or composition between the hybrids (Blakely et al., 1979). Dewar et al. (1997) reported that after steeping grain sorghum with dilute $\mathrm{NaOH}$, there was an increase in water uptake, which was seen more in 
Table 1 Initial kernel hardness and $\Delta$ mass extraction data for four sorghum hybrids

\begin{tabular}{lllll}
\hline $\begin{array}{l}\text { Sorghum } \\
\text { name }\end{array}$ & $\begin{array}{l}\text { Pigmented } \\
\text { testa layer }\end{array}$ & Description & Hardness* & \multicolumn{1}{c}{$\Delta$ Mass $\%^{\dagger}$} \\
\hline SP3303 & No & White & $77.70 \pm 2.53$ & $-4.377 \pm 1.090$ \\
MMR & No & Red & $76.35 \pm 1.35$ & $-0.167 \pm 0.237$ \\
$381 / 73$ & Yes & $\begin{array}{l}\text { Brown, } \\
\text { Tannin }\end{array}$ & $65.46 \pm 1.96$ & $-11.337 \pm 0.775$ \\
Sumac & Black & $55.13 \pm 1.80$ & $-15.675 \pm 0.342$ \\
Tx430 & No & \begin{tabular}{l} 
Bla \\
\hline
\end{tabular}
\end{tabular}

*Single-kernel characterisation system (SKCS) hardness index.

${ }^{\dagger} \Delta$ Mass $\%=\left(\right.$ mass $_{\text {after drying }}-$ mass $\left._{\text {original }}\right) /($ mass original $) \times 100$.

cultivars without tannins. The authors concluded that the $\mathrm{NaOH}$ solution reacted with pericarp cell wall material, resulting in higher quantities of phenolic compounds being extracted.

\section{Acetone extraction of flour phenolic compounds}

Phenolic compounds from whole-grain sorghum flour were extracted using a $75 \%$ acetone solution to show the effectiveness of the $\mathrm{NaOH}$ extraction method. An aqueous acetone extraction method was chosen over methanol and ethanol solutions by previous optimisations on sorghum flour (data not shown). Awika et al. (2005) employed aqueous acetone for phenol and antioxidant activity on sorghum bran. The AOC was determined on a per gram whole flour basis (Fig. 1). There was no difference between the acetone and $\mathrm{NaOH}$ extraction methods for the white and red sorghums. Sumac extracted with $\mathrm{NaOH}$ did show a higher ORAC value than the acetone extraction method. Although less evident, the black sorghum (Tx430) also showed similar behaviour. ORAC values were higher in the Sumac treatment possibly because of the presence of tannins that was not found in the

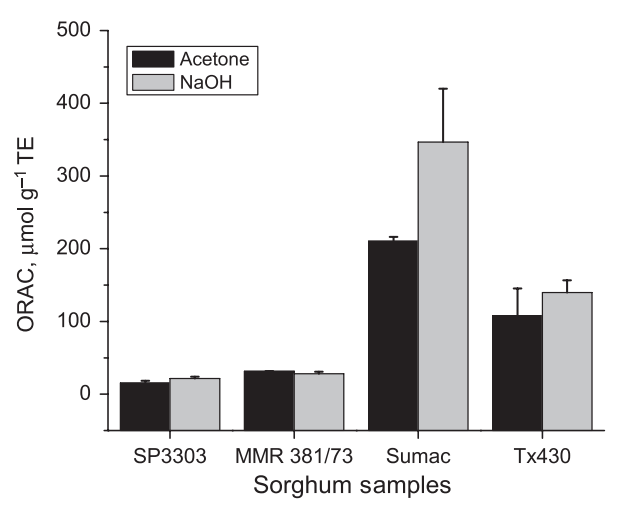

Figure 1 Antioxidant capacity values (day 0) of four sorghum hybrids that were extracted using $75 \%$ acetone (whole-grain flour) and $10 \%$ sodium hydroxide (intact whole-grain kernels). other sorghum treatments. Compared to the non-tannin samples, Sumac exhibited the highest AOC in agreement with the trends shown in a review by Awika \& Rooney (2004). For AOC analysis, the $\mathrm{NaOH}$ extraction was at least equally or more efficient than the acetone method. The data showed that alkaline extraction of phenolic compounds from whole grains may represent a viable alternative to a multistep procedure of decortication and/or milling to flour and subsequently extracted. Folin-Ciocalteu reagent does not react in alkaline conditions; thus, total phenolic content was not reported (Singleton et al., 1999). In addition, the extraction of phenolic compounds from flour could not be effective using the alkaline method because it tends to form clumps, making the results inconsistent.

\section{Antioxidant capacity stability}

Stability of the $\mathrm{NaOH}$ extracts was determined based on AOC in various conditions (Fig. 2). The liquid extracts were analysed by ORAC at days $0,4,16$ and 32. All untreated non-tannin sorghums showed more stable AOC values whilst neutralised liquid samples were less stable and lost about half their AOC by day 32 at ambient conditions. Only Sumac showed a decrease in AOC under both conditions. The untreated Sumac extract was the least stable with the original AOC value reduced to about half. Makkar \& Becker (1996) reported that the change in chemical structure of the tannin may be due to alkaline treatment. This is critical because tannins are responsible for the AOC (Dykes et al., 2005). Structure change could affect the extractability of the phenolic compounds. If compounds aggregated or formed complexes in the alkali conditions, then it would be more difficult to extract larger compounds; however, if the compounds degrade, there should be no real effect on extractability. There did not appear to be any change in the colour of the extracts over time (no data presented).

Samples of each treated and non-treated $\mathrm{NaOH}$ extracts were freeze dried, redissolved to the same volume 32 days after extraction and compared to the original AOC on day 0 (Fig. 3). All the dried samples, either basic or neutral, showed some reduction in AOC. However, the degree of loss in AOC varied for each sorghum hybrid. The dried white and red sorghum samples had little change in AOC. Dried, neutral extracts were the least stable in the Sumac and black sorghums. Further tests would need to be conducted on stability of the $\mathrm{NaOH}$ extracts in various conditions such as storage temperature and postextraction $\mathrm{pH}$.

Sorghum contains various phytochemicals, as referenced earlier, but the majority of focus has been on black and tannin sorghums. A review by Awika \& 

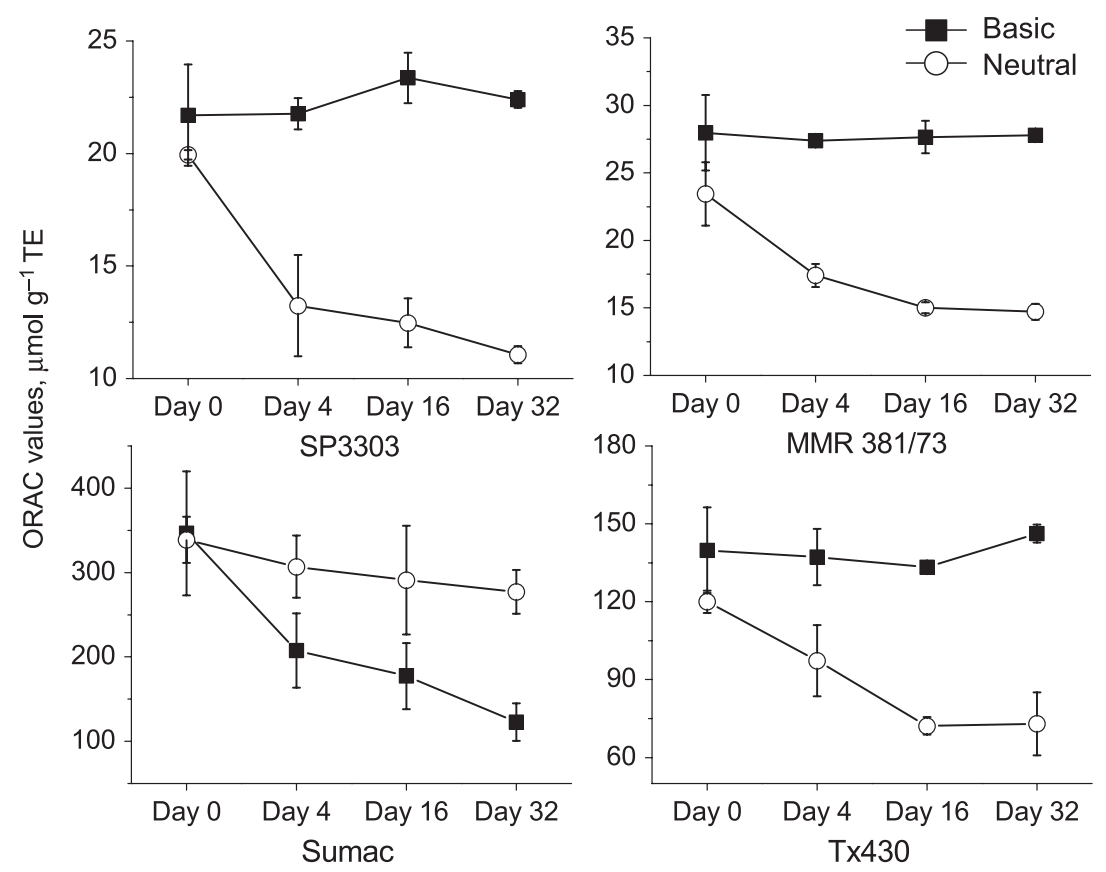

Figure 2 Stability of the oxygen radical absorbance capacity values of neutralised and untreated extracts from sorghum grain during 32 days of storage at ambient temperature.

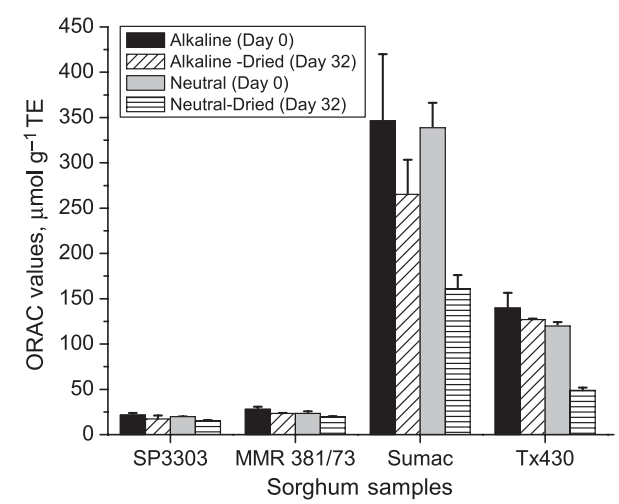

Figure 3 Oxygen radical absorbance capacity values of extracts from sorghum grain that were freeze dried and measured after 32 days.

Rooney (2004) reported higher AOC in black and high tannin sorghum bran than in blueberries and other high antioxidant fruits. Black sorghums have a high amount of anthocyanins particularly 3-deoxyanthocyanidins (Awika \& Rooney, 2004). These are different from most anthocyanins because of the lack of a hydroxyl group at the C-3 position with good stability in acidic conditions. Because of the added stability of sorghum anthocyanins, it may be a viable source of anthocyanins for usage as food additives, vitamins or anthocyanin standards.

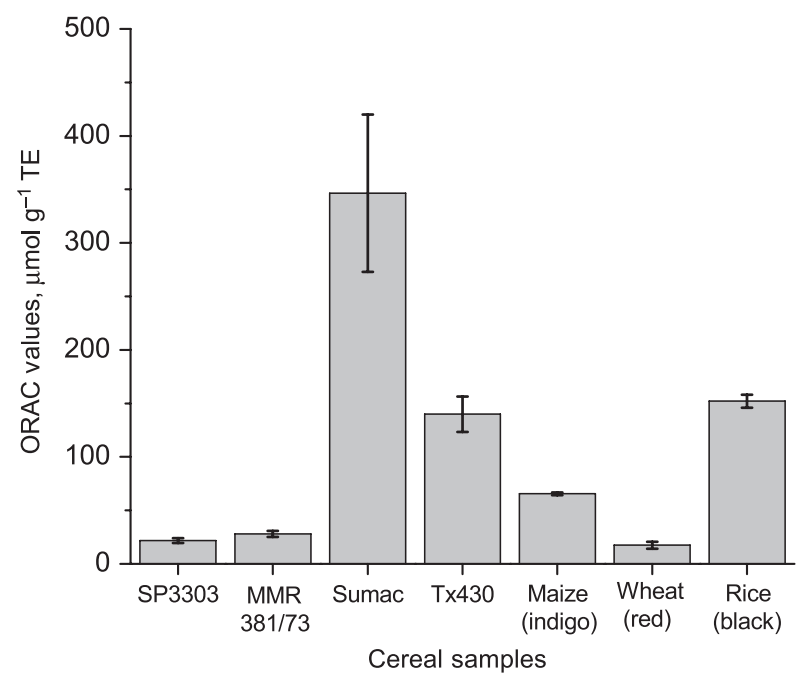

Figure 4 Comparison of oxygen radical absorbance capacity values of sorghum and other selected cereal grains.

\section{Antioxidant capacity comparison amongst grains}

To show the efficacy of this extraction method beyond sorghum, the AOC of the four sorghum samples was compared to intact whole-grain indigo maize, red wheat and black rice (Fig. 4). Black rice exhibited the highest AOC value amongst the non-sorghum grains. 
Sumac exhibited a twofold higher AOC compared to black rice. Black rice and black sorghum (Tx430) had similar AOC. The data suggests that the $\mathrm{NaOH}$ method to extract phenolic compounds from whole grain may be extended to other cereal types.

\section{Conclusions}

Direct extraction of the phenolic compounds using an alkaline solvent can be achieved without the need to decorticate or grind the grain. Furthermore, alkaline extraction may hold advantages over the traditional decortications method with grains of soft endosperms. Use of this method could improve the quality whether the goal is pure flour or bran. $\mathrm{NaOH}$ would remove colour as well as bran, and colour of flour is a measurement of quality. In the mechanical process, the shape of the grain can affect the ability to evenly decorticate. Alkali debranning eliminates this, lowering the amount of rejected misshapen grain. Improving quality, yield and percent rejected grain can increase revenue. One disadvantage is the interference with Folin-Ciocalteu reagent for the total phenolic assays although it is clear from the ORAC values that phenolic compounds are being extracted. AOC was stable for at least a month, and the method is applicable to other cereal grains. Implementing this method for routine analysis would require further optimisation as far as treatments and the types of information desired.

\section{Acknowledgments}

The authors would like to thank José A. Leal for preparing flour samples and SKCS analysis.

\section{References}

Awika, J.M. \& Rooney, L.W. (2004). Sorghum phytochemicals and their potential impact on human health. Phytochemistry, 65, 11991221.

Awika, J.M., McDonough, C.M. \& Rooney, L.W. (2005). Decorticating sorghum to concentrate healthy phytochemicals. Journal of Agricultural and Food Chemistry, 53, 6230-6234.

Bean, S.R., Chung, O.K., Tuinstra, M.R., Pedersen, J.F. \& Erpelding, J. (2006). Evaluation of the single kernel characterization sys- tem (SKCS) for measurement of sorghum grain attributes. Cereal Chemistry, 83, 108-113.

Blakely, M.E., Rooney, L.W., Sullins, R.D. \& Miller, F.R. (1979). Microscopy of the pericarp and the testa of different genotypes of sorghum. Crop Science, 19, 837-842.

Blessin, C.W., Deatherage, W.L. \& Inglett, G.E. (1970). Chemical dehulling of dent corn. Cereal Chemistry, 47, 303-308.

Cao, G. \& Prior, R. (1999). Measurement of oxygen radical absorbance capacity in biological samples. Methods in Enzymology, 299, $50-62$.

Cuevas Montilla, E., Hillebrand, S., Antezana, A. \& Winterhalter, P. (2011). Soluble and bound phenolic compounds in different bolivian purple corn (Zea mays L.) cultivars. Journal of Agricultural and Food Chemistry, 59, 7068-7074.

Dewar, J., Orovan, E. \& Taylor, J.R.N. (1997). ffect of alkaline steeping on water uptake and malt quality in sorghum. Journal of the Institute of Brewing, 103, 283-285.

Dykes, L. \& Rooney, L.W. (2006). Sorghum and millet phenols and antioxidants. Journal of Cereal Science, 44, 236-251.

Dykes, L., Rooney, L.W., Waniska, R.D. \& Rooney, W.L. (2005). Phenolic compounds and antioxidant activity of sorghum grains of varying genotypes. Journal of Agricultural and Food Chemistry, 53, 6813-6818.

Huang, D., Ou, B., Hampsch-Woodill, M., Flanagan, J. \& Prior, R. (2002). High-throughput assay of oxygen radical absorbance capacity (ORAC) using a multichannel liquid handling system coupled with a microplate fluorescence reader in 96-well format. Journal of Agricultural and Food Chemistry, 50, 4437-4444.

Lazaro, E.L. \& Favier, J.F. (2000). lkali debranning of sorghum and millet. Cereal Chemistry, 77, 717-720.

Makkar, H.P.S. \& Becker, K. (1996). Effect of pH, temperature, and time on inactivation of tannins and possible implications in detannification studies. Journal of Agricultural and Food Chemistry, 44, $1291-1295$.

Medina, M.B. (2011). Simple and rapid method for the analysis of phenolic compounds in beverages and grains. Journal of Agricultural and Food Chemistry, 59, 1565-1571.

Mistry, A.H. \& Eckhoff, S.R. (1992). Dry milling and physical characteristics of alkali-debranned yellow dent corn. Cereal Chemistry, 69, 82-84.

Mwansaru, M.A., Reichert, R.D. \& Mukuru, S.Z. (1988). Factors affecting the abrasive dehulling efficiency of high-tannin sorghum. Cereal Chemistry, 65, 171-174.

O'Kennedy, M.M., Grootboom, A. \& Shewry, P.R. (2006). Harnessing sorghum and millet biotechnology for food and health. Journal of Cereal Science, 44, 224-235.

Pedersen, J.F., Martin, C.R., Felker, F.C. \& Steele, J.L. (1996). Application of the single kernel wheat characterization technology to sorghum grain. Cereal Chemistry, 73, 421-423.

Singleton, V.L., Othofer, R. \& Lamuela-Raventós, R.M. (1999). Analysis of total phenols and other oxidation substrates and antioxidants by means of Folin-Ciocalteu reagent. Methods in Enzymology, 299, 152-178. 